ARTICLE

https://doi.org/10.1038/s41467-021-25048-x

\title{
Electrocatalytic upcycling of polyethylene terephthalate to commodity chemicals and $\mathrm{H}_{2}$ fuel
}

Hua Zhou (1) 1,4, Yue Ren ${ }^{2,4}$, Zhenhua Li ${ }^{2,4}$, Ming Xu², Ye Wang ${ }^{1}$, Ruixiang Ge ${ }^{1}$, Xianggui Kong ${ }^{2}$, Lirong Zheng ${ }^{3}$ \& Haohong Duan (D) ${ }^{1 凶}$

Plastic wastes represent a largely untapped resource for manufacturing chemicals and fuels, particularly considering their environmental and biological threats. Here we report electrocatalytic upcycling of polyethylene terephthalate (PET) plastic to valuable commodity chemicals (potassium diformate and terephthalic acid) and $\mathrm{H}_{2}$ fuel. Preliminary techno-economic analysis suggests the profitability of this process when the ethylene glycol (EG) component of PET is selectively electrooxidized to formate ( $>80 \%$ selectivity) at high current density $\left(>100 \mathrm{~mA} \mathrm{~cm}^{-2}\right)$. A nickel-modified cobalt phosphide $\left(\mathrm{CoNi}_{0.25} \mathrm{P}\right)$ electrocatalyst is developed to achieve a current density of $500 \mathrm{~mA} \mathrm{~cm}^{-2}$ at $1.8 \mathrm{~V}$ in a membrane-electrode assembly reactor with $>80 \%$ of Faradaic efficiency and selectivity to formate. Detailed characterizations reveal the in-situ evolution of $\mathrm{CoNi}_{0.25} \mathrm{P}$ catalyst into a low-crystalline metal oxy(hydroxide) as an active state during EG oxidation, which might be responsible for its advantageous performances. This work demonstrates a sustainable way to implement waste PET upcycling to value-added products.

\footnotetext{
${ }^{1}$ Department of Chemistry, Tsinghua University, Beijing, China. ${ }^{2}$ State Key Laboratory of Chemical Resource Engineering, College of Chemistry, Beijing University of Chemical Technology, Beijing, China. ${ }^{3}$ Institute of High Energy Physics, The Chinese Academy of Sciences, Beijing, China. ${ }^{4}$ These authors contributed equally: Hua Zhou, Yue Ren, Zhenhua Li. 凶email: hhduan@mail.tsinghua.edu.cn
} 
$\mathrm{O}$ ver 8 billion tons of plastics have been produced to date, and $79 \%$ of them are discarded and accumulated in landfills or aquatic systems $s^{1,2}$, representing a severe environmental and biological threat ${ }^{3-6}$. Plastic reclaim is essential for non-renewable resource saving, thereby reducing $\mathrm{CO}_{2}$ emission, according to the circular economy principle ${ }^{7,8}$. Conventional plastic recycling strategies (e.g., mechanical methods) had limited success $(<10 \%$ recycling rate) and the reproduced materials are suffering from inferior properties compared with the virgin plastic, and such process is often called downcycling model $^{1,5}$. In this respect, chemical reclaim provides an alternative route to get more value from wastes by catalytically processing them to high-quality monomer subunits ${ }^{5,9-11}$ or upcycling into value-added products ${ }^{7,12}$. The success of these approaches would rely on the efficiency and selectivity of the catalysts and also the sustainability and profitability of the process.

Polyethylene terephthalate (PET) is produced $\sim 70$ million tons annually for packaging and textiles ${ }^{10}$, but only a small fraction $(<20 \%)$ of them are recycled mainly via mechanical method (Fig. 1a) $)^{5}$. Thermal recycling approaches (such as, hydrogenolysis ${ }^{13}$ and glycolysis ${ }^{14}$ ) lead to the recovery of monomers (terephthalic acid (PTA) or bis(2-hydroxyethyl) terephthalate) under elevated temperatures. The polyester nature of PET makes it readily decomposed into its monomers under mild conditions catalyzed by base $e^{2,11}$ or hydrolases ${ }^{10}$, which can be further transformed into valuable products. Recently, Erwin and co-workers reported a photoreforming strategy for converting PET waste into clean $\mathrm{H}_{2}$ fuel and oxygenates (i.e., formate, glyoxal, and acetate) under mild conditions ${ }^{2,15}$. The ethylene glycol (EG) component of PET is readily oxidized by photogenerated holes which improves $\mathrm{H}_{2}$ production rate from water. Despite the well-established methodology, the process still suffers from low spatial productivity and poor selectivity towards a single high-value oxidation product (Supplementary Table 1) ${ }^{16,17}$.

Electrocatalysis can be powered by renewable energy (solar, wind, and hydro) that represents a sustainable and attractive strategy to generate clean $\mathrm{H}_{2}$ from water at cathode and valueadded oxygenates from organic compounds at anode under mild conditions $^{18-21}$. It has obtained great advancements in efficient and selective transformation of various organic compounds, such as simple alcohols and renewable biomass-derived oxygenates, and varieties of valuable carbonyl chemicals such as formate ${ }^{22,23}$, acetate $^{24,25}, 2,5$-furandicarboxylate ${ }^{26}$, adipate ${ }^{19}$ can be obtained. However, the electrocatalytic reforming of PET waste into valuable products is largely unexplored.

Here, we show an electrocatalytic strategy for PET waste upcycling to commodity chemicals of potassium diformate (KDF) and PTA paired with $\mathrm{H}_{2}$ production using a bifunctional $\mathrm{CoNi}_{0.25} \mathrm{P}$ electrocatalyst in $\mathrm{KOH}$ electrolyte (Fig. $1 \mathrm{~b}$ ). The PET is digested in alkaline solution to give its monomers including PTA and EG, and the latter is selectively (>90\%) undergoing C-C cleavage to formate over anodic $\mathrm{CoNi}_{0.25} \mathrm{P}$ catalyst in electrolyzer, alongside the $\mathrm{H}_{2}$ generation over the same catalyst at cathode. Subsequently, formic acid is used as an acidifier of the PET electrolyte for PTA precipitation and regeneration by filtration, and the resulting liquid stream is transformed into solid KDF by concentration and crystallization. Preliminary techno-economic analysis (TEA) estimates the net revenues of $\sim 350$ for upcycling per tonne of waste PET under commercially relevant current density $\left(>300 \mathrm{~mA} \mathrm{~cm}^{-2}\right)$. Comprehensive analysis of the material after reactions reveal the formation of metal phosphide/oxy (hydroxide) core-shell structure during cathodic hydrogen evolution reaction (HER) and a complete reconstruction of
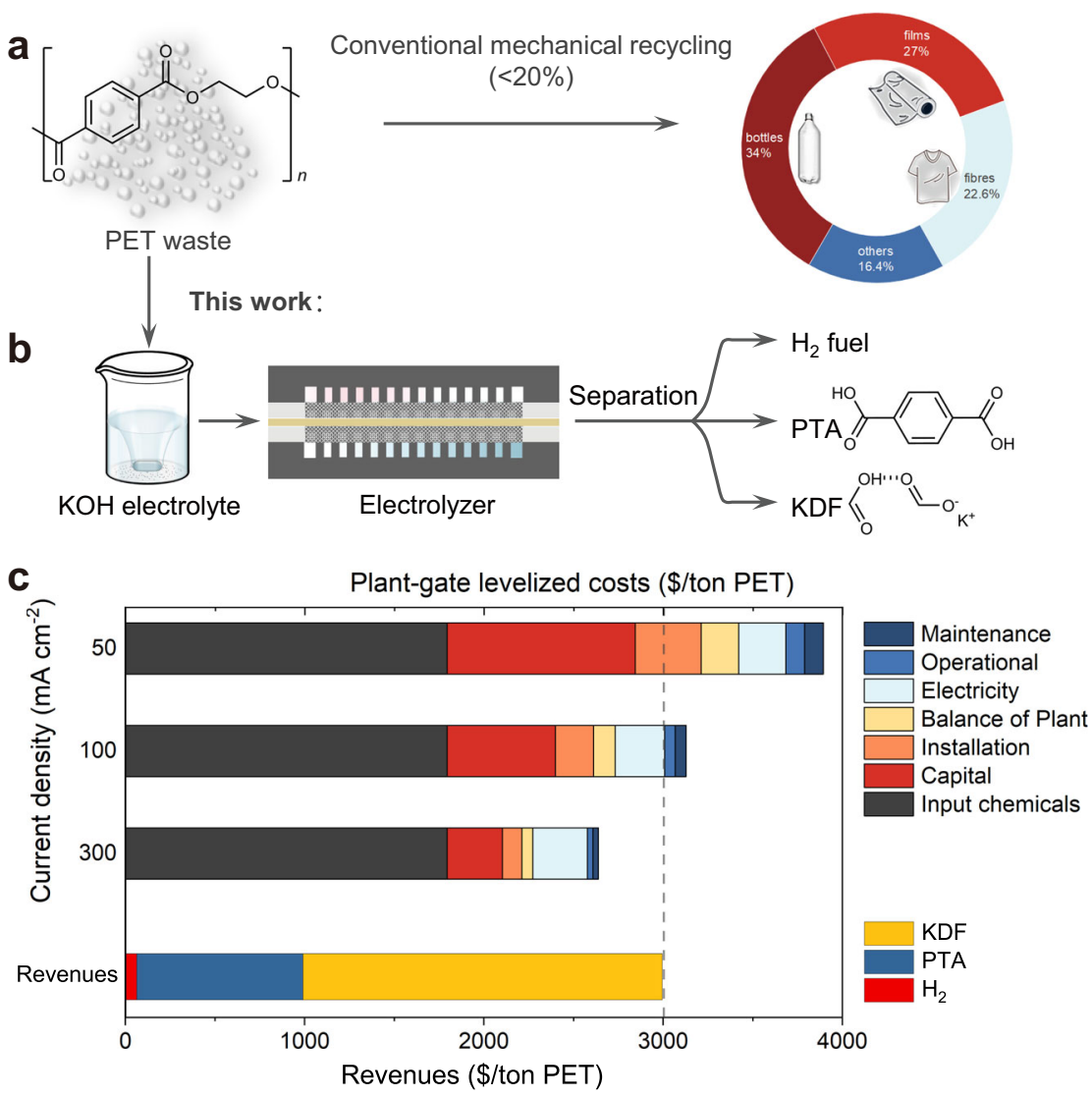

Fig. 1 Conceptual design. a Conventional route for PET recycling. b Electrocatalytic PET upcycling to commodity chemicals and $\mathrm{H}_{2}$ fuel (Route I). c Technoeconomic analysis (TEA) of Route I at different current density. 
phosphide to low-crystalline oxy(hydroxide) analogue under anodic conditioning, which might be responsible for its high catalytic performance.

\section{Results}

Conceptual design and techno-economic analysis. One key factor for the success of electrocatalytic PET reclaim is efficiently and selectively deriving value-added products to compensate the costs of the process ${ }^{20,27}$. Formic acid and formate are important industrial chemicals mainly used in animal feed (34\%) with increasing demand (Supplementary Fig. 1). In contrast, their derived functional commodity-KDF, known as $\mathrm{Formi}^{\mathrm{m}}-$ is an emerging and safe growth promoter for animals with the ban of antibiotic additives for feed ${ }^{28,29}$. In this context, we conceived an integrated process for PET waste upcycling toward targeted commodity chemicals (i.e., KDF, PTA) and clean fuel $\left(\mathrm{H}_{2}\right)$, denoted as Route I. As illustrated in Fig. 1b, the process is mainly composed of three steps: (i) KOH-catalyzed PET hydrolysis (Eq. 1), (ii) electroreforming (ER) of PET hydrolysate (Eq. 2), including EG oxidation (Eq. 3) and paired HER (Eq. 4), and (iii) formic acid-assisted products (KDF, PTA) separation (Supplementary Fig. 2).

Hydrolysis: $(\mathrm{PET})_{n}+(2 n-1) \mathrm{H}_{2} \mathrm{O} \rightarrow n \mathrm{C}_{8} \mathrm{H}_{6} \mathrm{O}_{4}(\mathrm{PTA})+n \mathrm{C}_{2} \mathrm{H}_{6} \mathrm{O}_{2}(\mathrm{EG})$

Electroreforming: $\mathrm{C}_{2} \mathrm{H}_{6} \mathrm{O}_{2}+2 \mathrm{OH}^{-} \rightarrow 2 \mathrm{HCOO}^{-}+3 \mathrm{H}_{2}$

$$
\begin{gathered}
\text { Anode: } \mathrm{C}_{2} \mathrm{H}_{6} \mathrm{O}_{2}+8 \mathrm{OH}^{-} \rightarrow 2 \mathrm{HCOO}^{-}+6 \mathrm{H}_{2} \mathrm{O}+6 \mathrm{e}^{-} \\
\text {Cathode }: 6 \mathrm{H}_{2} \mathrm{O}+6 \mathrm{e}^{-} \rightarrow 3 \mathrm{H}_{2}+6 \mathrm{OH}^{-}
\end{gathered}
$$

We then conducted a preliminary TEA to investigate the feasibility of this conceptual system using a model (Supplementary Figs. 2 and 3) adapted from literatures, reported by Sargent and coworkers $^{30-32}$. It suggests that the profitability of the process depends on the cost of renewable electricity, Faradaic efficiency to formate $\left(\mathrm{FE}_{\text {formate }}\right)$, and operating current density (Supplementary Fig. 4). With the development of renewable electricity, its cost continues to plummet to below ${ }^{31} 10$ cents $\mathrm{kWh}^{-1}$. In this context, ER of PET is of economic possibility when the electrocatalyst achieves high $\mathrm{FE}_{\text {formate }}(>80 \%)$ and high current density $\left(>100 \mathrm{~mA} \mathrm{~cm}^{-2}\right)$ (Fig. $1 \mathrm{c}$ and Supplementary Fig. 4).

Conventionally, the alkali PET hydrolysate is neutralized by mineral acids (e.g., $\mathrm{H}_{2} \mathrm{SO}_{4}$ ) for PTA precipitation, denoted as Route II (Supplementary Fig. 5a), if one only targets the recovery of PTA and EG monomers. The subsequent separation of EG and $\mathrm{K}_{2} \mathrm{SO}_{4}$ step requires more distillation equipment and intense energy because of the high boiling point $\left(197^{\circ} \mathrm{C}\right)$ and excellent water solubility of EG. In contrast, formic acid is used as the acidifier for PTA separation and KDF production in Route I, simplifying the separation process and improving the revenue of products. Even though the costs related to electrolysis is eliminated in Route II, TEA suggests that it is without profitability owing to the relatively low returns of the products (PTA, EG, and $\mathrm{K}_{2} \mathrm{SO}_{4}$ ) (Supplementary Fig. 5b). Similarly, there is low economic possibility for Route III (Supplementary Fig. 6) toward PTA, formic acid, $\mathrm{H}_{2}$, and $\mathrm{K}_{2} \mathrm{SO}_{4}$ as final products when using $\mathrm{H}_{2} \mathrm{SO}_{4}$ for separating products from the PET electrolyte.

Overall, the preliminary TEA result indicates the economic potential of the electrocatalytic upcycling of PET waste to KDF, PTA, and $\mathrm{H}_{2}$, and highlights the requirement of advanced and cost-effective electrocatalysts to realize EG oxidation to formate, ideally a bifunctional electrocatalyst for both the reactions, at commercially relevant current density $\left(>100 \mathrm{~mA} \mathrm{~cm}^{-2}\right)$ in high $\mathrm{FE}_{\text {formate }}$ and selectivity ( $\left.>80 \%\right)$.
Optimization of electrocatalyst for HER and EG oxidation. Transition metal-based phosphides (especially for earth-abundant $\mathrm{Co}$ and $\mathrm{Ni}$ ) are demonstrated to be efficient electrocatalyst in various reactions, including HER, oxygen evolution reaction (OER), and organic transformations ${ }^{33-35}$. To develop a bifunctional electrocatalyst for HER and EG oxidation, we synthesized a series of Co and Ni phosphides supported on nickel foam (NF) including $\mathrm{CoNi}_{x} \mathrm{P} / \mathrm{NF}(x=0,0.1,0.25,0.5$, the feed atomic ratios of $\mathrm{Ni} / \mathrm{Co}$ ) and $\mathrm{Ni}_{2} \mathrm{P} / \mathrm{NF}$ via tandem electrodeposition and phosphidation as illustrated in Supplementary Fig. 7. The nanoarray is composed of $\alpha$-phase metal hydroxide nanosheets that was obtained by electrodeposition (Supplementary Fig. 8) with following phosphidation to give metal phosphides (Supplementary Fig. 9 and Supplementary Table 2). For comparison, metal hydroxide-derived oxy(hydroxide) and oxide were also prepared (Supplementary Figs. 7, 10, and 11).

The as-prepared samples were evaluated for HER in an alkaline electrolyte $(1 \mathrm{M} \mathrm{KOH})$. As shown in Fig. $2 \mathrm{a}$, the $\mathrm{CoNi}_{0.25} \mathrm{P} / \mathrm{NF}$ exhibits the best performance among the samples with a low Tafel slope of $58.1 \mathrm{mV}$ decade $^{-1}$ (Supplementary Fig. 12), representing an advantageous material compared to the reported non-noble metal phosphides for HER (Supplementary Table 2). The improved HER activity of $\mathrm{CoNi}_{0.25} \mathrm{P} / \mathrm{NF}$ can be attributed to the decreased charge transfer resistance and increased electrochemically active surface area (Supplementary Fig. 13). Subsequently, we tested the oxidative performance of $\mathrm{CoNi}_{x} \mathrm{P} / \mathrm{NF}$ and $\mathrm{Ni}_{2} \mathrm{P} / \mathrm{NF}$ electrocatalysts in $1 \mathrm{M} \mathrm{KOH}$ without or with $0.3 \mathrm{M} \mathrm{EG}$. In the absence of EG, all the electrocatalysts exhibit comparative OER activity with similar onset potential around $1.51 \mathrm{~V}$ vs RHE (Fig. 2b). Whereas the onset potential of all the electrocatalysts shifts toward lower potential $(1.22-1.33 \mathrm{~V}$ vs $\mathrm{RHE})$ after introducing 0.3 M EG into electrolyte (Fig. 2c), indicating EG oxidation is thermodynamically more favorable than OER. Among these materials, $\mathrm{CoNi}_{0.25} \mathrm{P} / \mathrm{NF}$ and $\mathrm{CoNi}_{0.5} \mathrm{P} / \mathrm{NF}$ outperform other self-prepared $\mathrm{Co}, \mathrm{Ni}$ phosphides and report efficient electrocatalysts ( $\mathrm{NiFe}-\mathrm{LDH}$ and commercial $\mathrm{RuO}_{2}$ ) with lower onset potential and higher current density for EG oxidation under the same conditions (Fig. 2c). Together with their HER performances, the $\mathrm{CoNi}_{0.25} \mathrm{P} / \mathrm{NF}$ was selected as both the cathodic and anodic catalyst for further evaluation.

Scanning electron microscopy (SEM) and elemental mapping show the nanoarray structure of $\mathrm{CoNi}_{0.25} \mathrm{P}$ with homogenous distribution of $\mathrm{Co}, \mathrm{Ni}$, and $\mathrm{P}$ on matrix (Supplementary Fig. 14a-c). Furthermore, high-resolution transmission electron microscopy (HRTEM) reveals that small $\mathrm{Ni}_{2} \mathrm{P}$ nanoparticles are inter-connected with $\mathrm{CoP}$ particles, forming $\mathrm{CoP}-\mathrm{Ni}_{2} \mathrm{P}$ heterojunctions in $\mathrm{CoNi}_{0.25} \mathrm{P}$ material. In addition, $\mathrm{X}$-ray diffraction (XRD) Rietveld refinement and extended X-ray absorption finestructure spectroscopy (EXAFS) fitting were performed. They reveal the co-existence of $\mathrm{CoP}$ and $\mathrm{Ni}_{2} \mathrm{P}$ phase in $\mathrm{CoNi}_{0.25} \mathrm{P}$ (Supplementary Fig. 15), with an atomic $\mathrm{Co:Ni}$ ratio of approximately 1:0.13 (Supplementary Table 3), which is consistent with the results of inductively coupled plasma-atomic emission spectrometry (ICP-AES) and energy dispersive X-ray (EDX) analysis (Supplementary Table 4).

We then systematically compared the catalytic performances of $\mathrm{CoNi}_{0.25} \mathrm{P} / \mathrm{NF}$ with known electrocatalysts (i.e., $\mathrm{Pt} / \mathrm{C}, \mathrm{RuO}_{2}, \mathrm{NiFe}-$ $\mathrm{LDH} / \mathrm{NF}$ ) in EG oxidation and HER (Supplementary Figs. 16 and 17), and the results are summarized in Fig. $2 \mathrm{~d}$. Specifically, $\mathrm{CoNi}_{0.25} \mathrm{P} / \mathrm{NF}$ displays the highest $\mathrm{FE}_{\text {formate }}(91.3 \%)$ for selective $\mathrm{EG}$ oxidation with an excellent spatial productivity of $4.01 \mathrm{mmol} \mathrm{cm}^{-2} \mathrm{~h}^{-1}$ at $1.7 \mathrm{~V}$ vs RHE, as well as good HER activity. For precious metal catalysts (i.e., $\mathrm{Pt} / \mathrm{C}$ and $\mathrm{RuO}_{2}$ ), they fail to achieve efficient and selective EG transformation into formate, although they display excellent HER performances. Despite the ultra-low potential (0.67 V vs RHE) required for $\mathrm{Pt} / \mathrm{C}$ to achieve a current density of $50 \mathrm{~mA} \mathrm{~cm}^{-2}$ in 

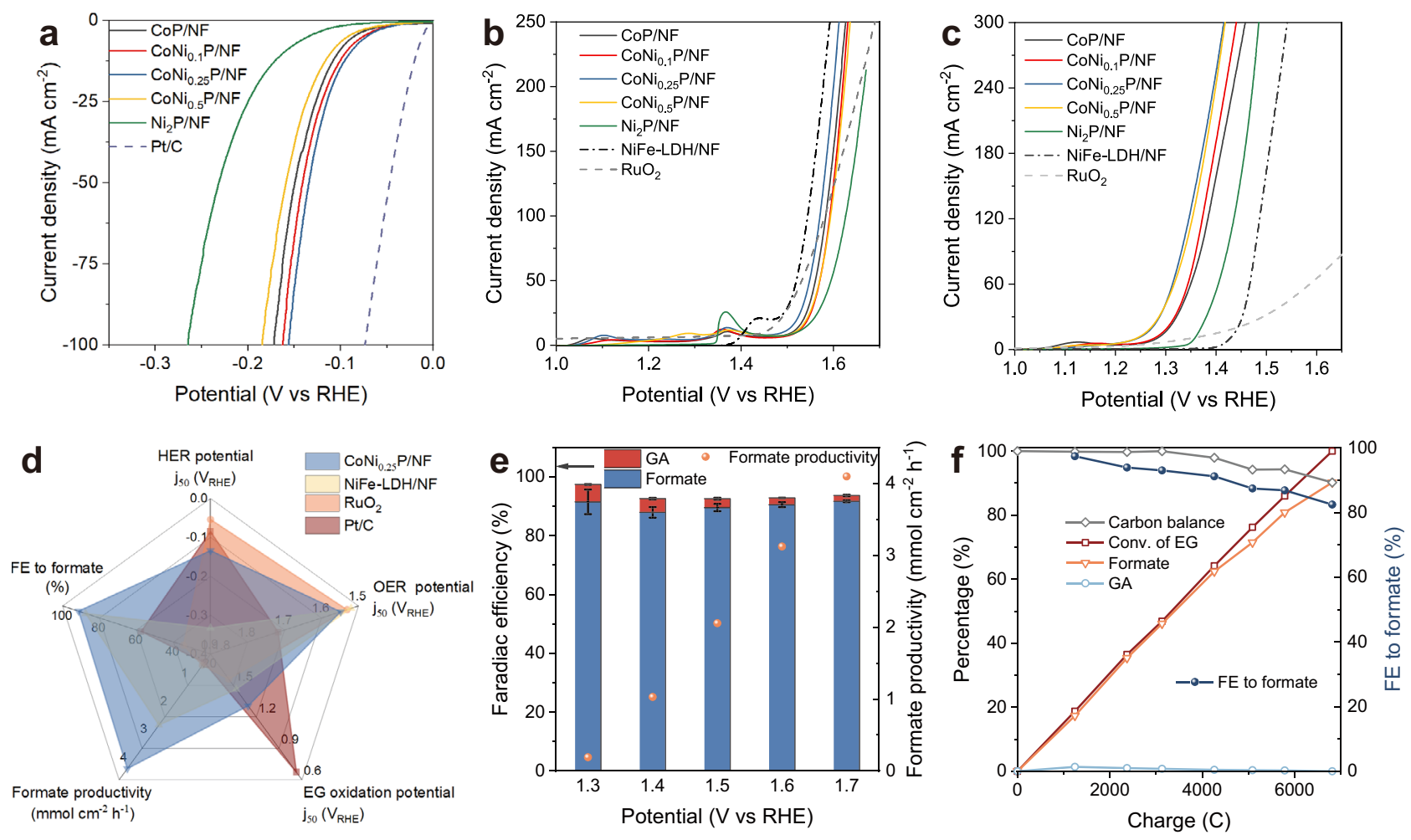

Fig. 2 Electrochemical evaluation of $\mathbf{C o N i} \mathbf{P}_{\mathbf{x}} \mathbf{P}$ and $\mathbf{~ N i}_{2} \mathbf{P}$ catalysts. a HER polarization curves (100\% iR corrected). b, $\mathbf{c} L S V$ curves (85\% iR corrected) for $\mathrm{OER}$ (b) and EG oxidation (c). d Comparison of the catalytic performances of $\mathrm{CoNi}_{0.25} \mathrm{P} / \mathrm{NF}$ and known catalysts. e FE and productivity of formate on $\mathrm{CoNi}_{0.25} \mathrm{P} / \mathrm{NF}$ at different potentials. Error bars correspond to the standard deviation of three measurements. $\mathbf{f}$ Kinetic curves for $\mathrm{EG}$ transformation at $1.5 \mathrm{~V}$ vs RHE. Reaction conditions: all experiments were performed in $1 \mathrm{M} \mathrm{KOH}$ in $\mathrm{H}$-cell separated by $\mathrm{AEM}$, the scan rate is $5 \mathrm{mV} \mathrm{s}^{-1}$ for all polarization curves, the EG concentration is $0.3 \mathrm{M}$.

EG oxidation (Fig. 2d), the main detected product is glycollate (GA, $\mathrm{FE}=68.8 \%$ at $1.0 \mathrm{~V}$ vs RHE) (Supplementary Figs. $16 \mathrm{~d}$ and 17 ), revealing the low reactivity of $\mathrm{Pt} / \mathrm{C}$ for oxidative $\mathrm{C}-\mathrm{C}$ bond cleavage. It is well in agreement with the catalytic performances of noble metals $(\mathrm{Pt}, \mathrm{Au}, \mathrm{Pd})$ for the oxidation of alcohols to aldehydes, in which the aldehydes are readily undergo an intermolecular Cannizzaro rearrangement to produce corresponding carboxylates and alcohols in base media 36,37 . NiFe-LDH/NF displays high activity for alkaline OER (Fig. 2b), consistent with literature ${ }^{38}$, whereas it is inferior to $\mathrm{CoNi}_{0.25} \mathrm{P} / \mathrm{NF}$ for breaking $\mathrm{C}-\mathrm{C}$ bond in EG to formate (Fig. $2 \mathrm{~d}$ and Supplementary Fig. 17). This result suggests that the active catalyst for OER may not be efficient for oxidative $\mathrm{C}-\mathrm{C}$ cleavage in EG. In addition, the lower activity of $\mathrm{CoNi}_{0.25}(\mathrm{OH})_{2} / \mathrm{NF}$-derived oxy(hydroxide) and oxide compared with its phosphide $\left(\mathrm{CoNi}_{0.25} \mathrm{P} / \mathrm{NF}\right)$ indicates the important role of phosphorization in improving the activity and selectivity for cutting $\mathrm{C}-\mathrm{C}$ in $\mathrm{EG}$ to formate (Supplementary Figs.17 and 18a). This may be attributed to that the phosphorization can accelerate the reconstruction of materials toward active catalyst ${ }^{39}$, and lower the charge transfer resistance (Supplementary Fig. 18b).

Electrocatalytic EG oxidation over $\mathrm{CoNi}_{\mathbf{0 . 2 5}} \mathrm{P} / \mathrm{NF}$. The EG transformation over $\mathrm{CoNi}_{0.25} \mathrm{P} / \mathrm{NF}$ anode was evaluated in a three-electrode $\mathrm{H}$-cell system separated by an anion exchange membrane (AEM). As shown in Supplementary Fig. 19a, large numbers of $\mathrm{H}_{2}$ bubbles are released from the cathode surface, while no bubble is observed on the anode in $1 \mathrm{M} \mathrm{KOH}$ with $\mathrm{EG}$ under $1.7 \mathrm{~V}$ vs RHE. By contrast, $\mathrm{O}_{2}$ bubbles are generated over the anode in a blank $1 \mathrm{M} \mathrm{KOH}$ anolyte under the same potential (Supplementary Fig. 19b). This is due to the fact that EG oxidation is thermodynamically more favorable than OER. The products of EG conversion were analyzed by high-performance liquid chromatography (HPLC). As shown in Supplementary Fig. 20a, formate is the dominant product with $\sim 90 \%$ of FE under a broad potential window (1.3-1.7 V vs RHE, Fig. 2e), revealing the high selectivity of $\mathrm{EG}$ transformation over $\mathrm{CoNi}_{0.25} \mathrm{P} / \mathrm{NF}$. Notably, the $\mathrm{CoNi}_{0.25} \mathrm{P} / \mathrm{NF}$ achieves $91.7 \%$ of $\mathrm{FE}_{\text {formate }}$ and $4.1 \mathrm{mmol} \mathrm{cm}^{-2} \mathrm{~h}^{-1}$ of formate productivity at a commercially relevant current density $\left(\sim 350 \mathrm{~mA} \mathrm{~cm}^{-2}\right)$ under $1.7 \mathrm{~V}$ vs RHE.

Additionally, HPLC analysis was adopted to track the dynamic conversion of EG over $\mathrm{CoNi}_{0.25} \mathrm{P} / \mathrm{NF}$ in a batch reaction. A small fraction of GA is the only observed product during EG oxidation (Fig. 2f and Supplementary Fig. 20a), indicative of the formation of glycolic aldehyde intermediate. Therefore, we performed the comparative electrochemical and kinetic evaluation using EG, glycolic aldehyde, and glycolic acid as starting substrate, respectively. As shown in Supplementary Fig. 20b, c, the reaction rates of the three substrates to formate follows the order: glycolic aldehyde $>$ EG $>$ glycolic acid. These results indicate that glycolic acid is not the main intermediate for glycolic aldehyde transformation to formate. Combining our results and recent literature $^{23}$, we propose that EG is initially oxidized to glycolic aldehyde, which is followed by rapid oxidative $\mathrm{C}-\mathrm{C}$ cleavage to formate (Supplementary Fig. 20d). Meanwhile, minor glycolic aldehyde is oxidized to glycolic acid, which is followed by slow $\mathrm{C}-\mathrm{C}$ cleavage to formate. After complete EG consumption, $90.2 \%$ yield of formate is obtained with good FE (82.5\%) and carbon balance (>90\%) (Fig. 2f). On the counterpart, water is reduced to hydrogen (Supplementary Fig. 20e).

It is known that the Ohmic resistance would induce a huge energy loss at high current density, which represents one particular challenge in many electrolysis technologies ${ }^{40,41}$. To overcome this obstacle, a zero-gap membrane-electrode assembly (MEA) flow 
a

$$
\mathrm{CoNi}_{0.25} \mathrm{P} / \mathrm{NF}
$$
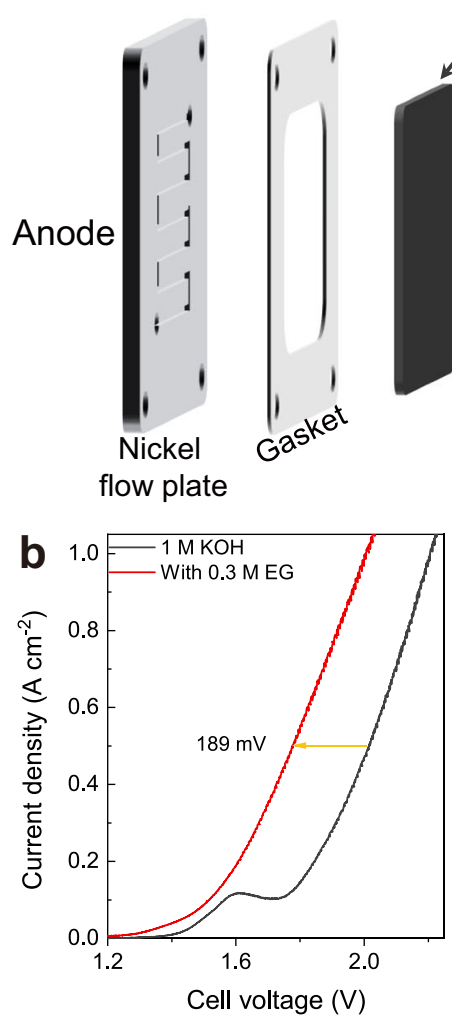
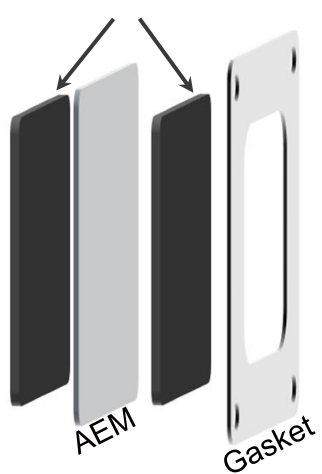
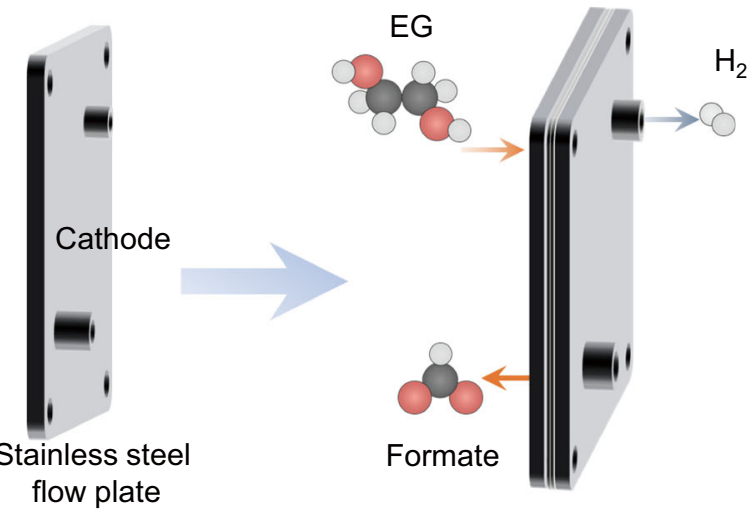

$\mathrm{H}_{2}$
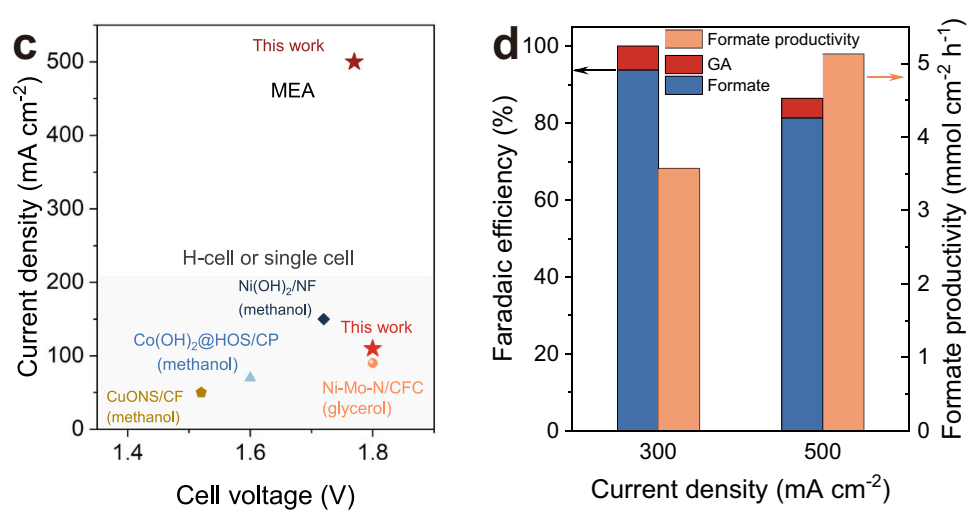

Fig. 3 Membrane-electrode assembly (MEA) for EG oxidation. a The MEA setup for paired HER(-)//EG oxidation( + ). b Polarization curves for water splitting and EG electrolysis in the MEA flow reactor at a scan rate of $10 \mathrm{mV} \mathrm{s}{ }^{-1}$. c Current density for formate production as a function of cell voltage in literatures and this work. d Faradaic efficiency and productivity as function of current density for EG oxidation.

reactor is designed for converting EG into formate paired with $\mathrm{H}_{2}$ production using $\mathrm{CoNi}_{0.25} \mathrm{P} / \mathrm{NF}$ as both the cathodic and anodic catalysts (Fig. 3a and Supplementary Fig. 21). The LSV polarization curves for traditional water splitting (HER//OER) and EG electrolysis (HER//EG oxidation) were acquired on this setup (Fig. 3b). The near-parallel polarization curves are presented for water splitting and EG electrolysis, showing $\sim 189 \mathrm{mV}$ decrease of cell voltage for reaching the same current density in the presence of EG in analyte, which in turn increases the cathodic energy efficiency. Compared with common $\mathrm{H}$-cell or single cell for anodic formate production from alcohols (Supplementary Fig. 22 and Supplementary Table 5$)^{23,42-44}$, the MEA reactor reaches a significantly higher current density $\left(500 \mathrm{~mA} \mathrm{~cm}^{-2}\right)$ at a low cell voltage $(<1.8 \mathrm{~V})$ (Fig. 3c). Moreover, the EG oxidation at a constant current density of 300 and $500 \mathrm{~mA} \mathrm{~cm}^{-2}$ in MEA give formate productivity of 3.6 and $5.1 \mathrm{mmol} \mathrm{cm}^{-2} \mathrm{~h}^{-1}$ (Fig. 3d), respectively, with good FE $(>80 \%)$, representing one of the most advantageous systems (Supplementary Table 5).

PET upcycling. In the light of the above foundations, we aim to demonstrate the proof-of-concept production of $\mathrm{KDF}, \mathrm{PTA}$, and $\mathrm{H}_{2}$ from a real-world PET plastic. Initially, the polyester structure of PET was readily hydrolyzed into its monomers (PTA and EG) in an aqueous $\mathrm{KOH}$ solution at $60^{\circ} \mathrm{C}$ with high yield (96.7\%) (Supplementary Fig. 23). The PET hydrolysate was then used as the analyte for the MEA electrolyzer (Fig. 4a), in which EG was selectively oxidized to formate (Supplementary Fig. 24). After electrolysis, the PET hydrolysate was transformed into terephthalate and formate in the electrolyte. The PET electrolyte was then acidified by formic acid to regenerate pure PTA (Supplementary Figs. 25 and 26). As shown in the Sankey diagram of mass flow analysis (Fig. 4b), $1 \mathrm{~kg}$ of
PET feedstock finally gave $389.2 \mathrm{~g}$ formate, $818.5 \mathrm{~g}$ PTA, and $16.9 \mathrm{~g}$ $\mathrm{H}_{2}$. After PTA separation, the filtrate stream contains formic acid and potassium formate, which was used for the synthesis of KDF through condensation and crystallization processes. Finally, 70\% yield of white KDF crystal was obtained and confirmed by Fourier transformation infrared spectroscopy (FT-IR) and XRD (Fig. 4c, d).

In practical conditions, waste PET usually contain impurities, such as polyolefins ${ }^{45}$, poly(lactic acid) (PLA), and lipids ${ }^{2}$. The base inaccessible polyolefins can be removed from the hydrolysate during the pre-treatment by simple filtration (Supplementary Fig. 27a $)^{16}$. Then, the lactate and glycerol from digested PLA and lipids can also be transformed to acetate and formate, respectively (Supplementary Fig. 27b, c). The acetic acid is also a common growth promoter for animals, which makes the process with some extent of compatibility for impure PET waste.

Although we demonstrated the HER//PET ER process in this work, replacing cathodic HER with other reductive organic transformations has the possibility to improve the profitability of PET reclaim. Particularly, the cost of formic acid production from electrocatalytic carbon dioxide reduction $\left(\mathrm{CO}_{2} \mathrm{RR}\right)$ is estimated to be $\sim 180 \$$ ton $^{-1}$, lower than the market price $\left(400 \$ \text { ton }^{-1}\right)^{46}$. In this context, pairing $\mathrm{CO}_{2} \mathrm{RR} / / \mathrm{PET}$ ER is capable of increasing the revenues more than $200 \$$ ton $^{-1}$ PET than that of HER//PET ER setup (Supplementary Fig. 28). However, more efforts are needed for this concept that is convergently transforming gaseous and solid wastes into valuable $\mathrm{KDF}$, especially the reactor design.

Catalyst stability and structural evolution. The operating stability of $\mathrm{CoNi}_{0.25} \mathrm{P} / \mathrm{NF}$ was evaluated at a constant potential of $1.7 \mathrm{~V}$ vs RHE for $39 \mathrm{~h}$ and $1.5 \mathrm{~V}$ vs RHE for $33 \mathrm{~h}$ in $\operatorname{HER}(-) / / \mathrm{EG}$ oxidation $(+)$ system. As shown in Fig. $5 \mathrm{a}, \mathrm{CoNi}_{0.25} \mathrm{P} / \mathrm{NF}$ 

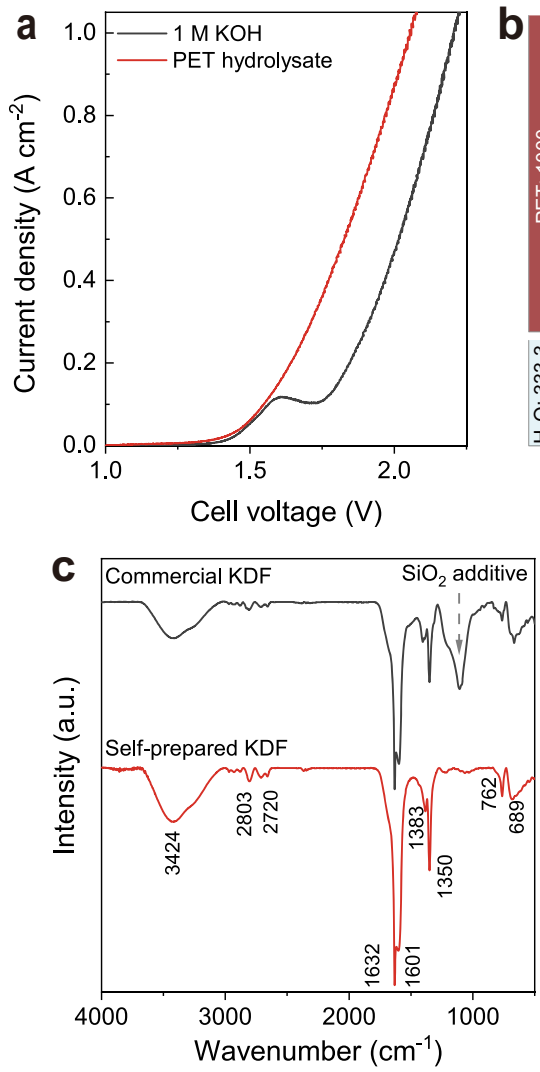
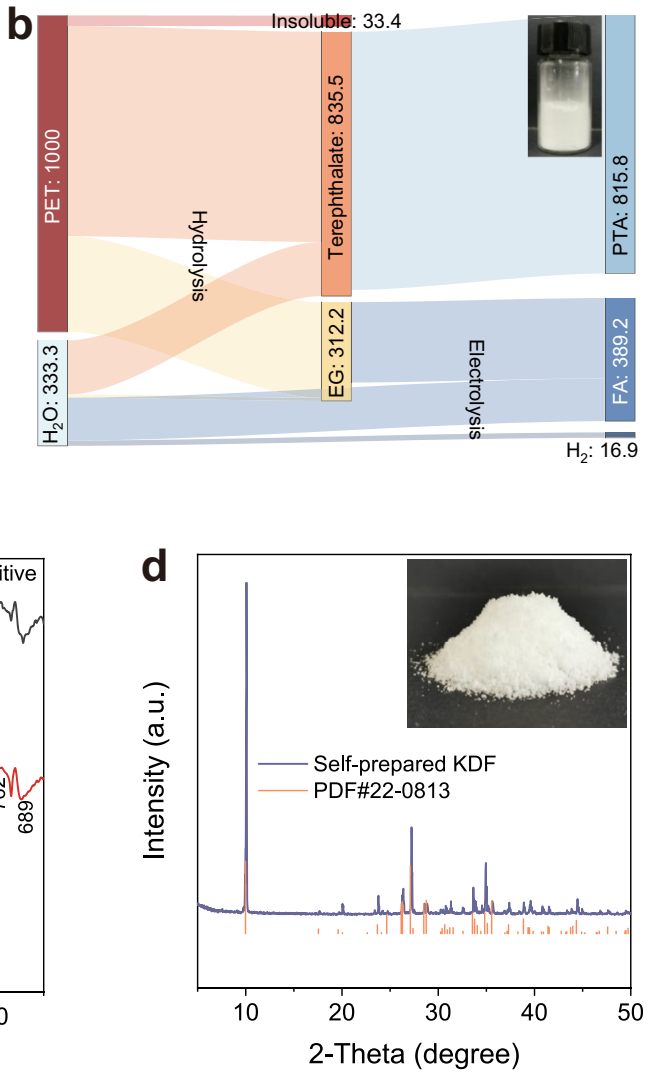

Fig. 4 PET upcycling. a Polarization curves for electrolysis of PET hydrolysate. b Sankey diagram for the mass flow of PET upcycling. Photograph of separated high-purity PTA is shown (inset). c FT-IR spectra of self-prepared and commercial KDF. d XRD pattern and photograph (inset) of self-prepared KDF. a.u.: arbitrary units.

maintains a current of around $350 \mathrm{~mA} \mathrm{~cm}^{-2}$ at $1.7 \mathrm{~V}$ vs RHE and $180 \mathrm{~mA} \mathrm{~cm}^{-2}$ at 1.5 vs RHE with high $\mathrm{FE}$ and selectivity of formate $(80-95 \%)$, indicating the high stability of $\mathrm{CoNi}_{0.25} \mathrm{P} / \mathrm{NF}$ for EG oxidation and HER. It also exhibits excellent stability for water splitting at $1.7 \mathrm{~V}$ vs RHE for $60 \mathrm{~h}$ with a steady current density of $\sim 159 \mathrm{~mA} \mathrm{~cm}^{-2}$ (Supplementary Fig. 29a).

It should be noted that an increase of current density (20-40 $\mathrm{mA} \mathrm{cm}{ }^{-2}$ ) in both water splitting and EG oxidation was observed in the initial period $(<1 \mathrm{~h})$ when using a virgin $\mathrm{CoNi}_{0.25} \mathrm{P} / \mathrm{NF}$ catalyst (Supplementary Fig. 29a, b), suggesting a possible catalyst activation process. This might be a result of catalyst surface reconstruction, which has been identified in many electrocatalysts (especially for OER) $39,47,48$ and photocatalysts ${ }^{49,50}$. For better understanding of the reconstruction of the catalyst, a carbon cloth-supported $\mathrm{CoNi}_{0.25} \mathrm{P}$ catalyst was prepared (Supplementary Fig. 30) to eliminate the interference of $\mathrm{NF}$ matrix in characterization of materials after EG oxidation reactions as well as HER and OER at $1.7 \mathrm{~V}$ vs RHE. The combined results of TEM, SAED, XRD, and elemental analysis (Fig. 5b and Supplementary Fig. 31) reveal that the crystalline structure and composition of $\mathrm{CoNi}_{0.25} \mathrm{P}$ are well retained after HER. In contrast, the $\mathrm{CoNi}_{0.25} \mathrm{P}$ catalyst undergoes complete reconstruction after OER and EG oxidation reactions, and it transforms into a low crystalline metal oxy(hydroxide) analogue (Fig. 5c, d and Supplementary Figs. 32 and 33), similar to recently reported $\mathrm{Co}_{9} \mathrm{~S}_{8}$ catalyst for alkaline $\mathrm{OER}^{47}$.

Moreover, the Raman spectrum of the spent $\mathrm{CoNi}_{0.25} \mathrm{P}$ catalyst for HER displays multiple peaks, including a collection of peaks at $130-400 \mathrm{~cm}^{-1}$ corresponding to $\mathrm{CoP}^{51}$, overlapped peaks at $410-720 \mathrm{~cm}^{-1}$ for $\mathrm{CoO}_{x}(\mathrm{OH})_{y}^{52,53}$, and a peak at $1056 \mathrm{~cm}^{-1}$ of
$\mathrm{PO}_{x}$ (Fig. 5e). This can be explained by the oxidation and dissolution of transition metal phosphide in alkaline media and redeposition to form an amorphous metal oxy(hydroxide) shell structure over $\mathrm{CoNi}_{0.25} \mathrm{P}^{33}$. However, only the peaks of $\mathrm{CoO}_{x}(\mathrm{OH})_{y}$ are observed in the spectra of the spent $\mathrm{CoNi}_{0.25} \mathrm{P}$ catalysts after OER and EG oxidation (Fig. 5e), which is consistent with the results of XRD, HRTEM, and elemental analysis (Supplementary Figs. 32 and 33).

We further investigated the electronic and geometric structures of the virgin and spent $\mathrm{CoNi}_{0.25} \mathrm{P}$ catalyst using $\mathrm{X}$-ray absorption near-edge structure (XANES) and EXAFS. Both Co and Ni Kedge XANES spectra of the spent $\mathrm{CoNi}_{0.25} \mathrm{P}$ of HER slightly shift toward higher-energy region (Fig. $5 f$ and Supplementary Fig. 34) compared with the virgin $\mathrm{CoNi}_{0.25} \mathrm{P}$ material, indicating a moderate oxidation of $\mathrm{Co}$ and $\mathrm{Ni}$. The adsorption energy and white line intensity of Co XANES profiles for the spent $\mathrm{CoNi}_{0.25} \mathrm{P}$ catalysts of OER and EG oxidations are significantly increased and similar with the spectrum of $\mathrm{CoNi}_{0.25} \mathrm{OOH}$ reference, suggesting the oxidation state of $\mathrm{Co}$ are predominant in +3 valence. These results are also confirmed by XPS analysis (Supplementary Fig. 35). Moreover, the EXAFS and wavelet transform (WT) analysis of EXAFS spectra also verify the phenomenon that $\mathrm{CoNi}_{0.25} \mathrm{P}$ catalyst remains its main structure during HER, while it evolves into coordination unsaturated metal oxy(hydroxide) analogue during anodic EG oxidation (Fig. 5g, h).

As illustrated in Fig. 5i, the starting $\mathrm{CoNi}_{0.25} \mathrm{P}$ material evolves into a $\mathrm{CoNi}_{0.25} \mathrm{P} / \mathrm{CoNi}_{0.25} \mathrm{O}_{x}(\mathrm{OH})_{y}$ core-shell structure at cathode, while it is drastically oxidized and reconstructed into lowcrystalline $\mathrm{CoNi}_{0.25} \mathrm{O}_{x}(\mathrm{OH})_{y}$ at anode. The EXAFS spectra at different reaction times reveal that the reconstruction of virgin 
a
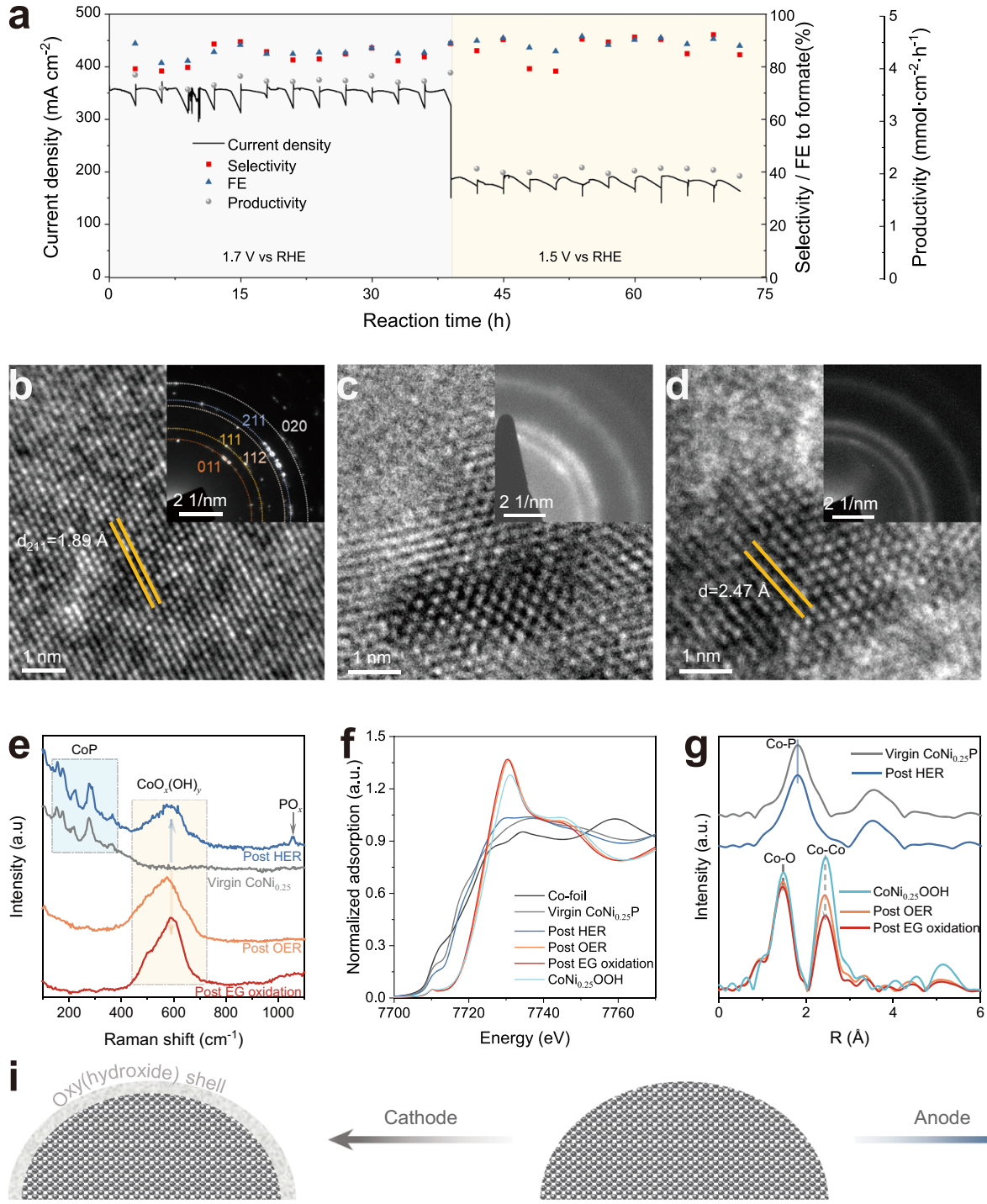

$\mathrm{CoNi}_{0.25} \mathrm{P}$
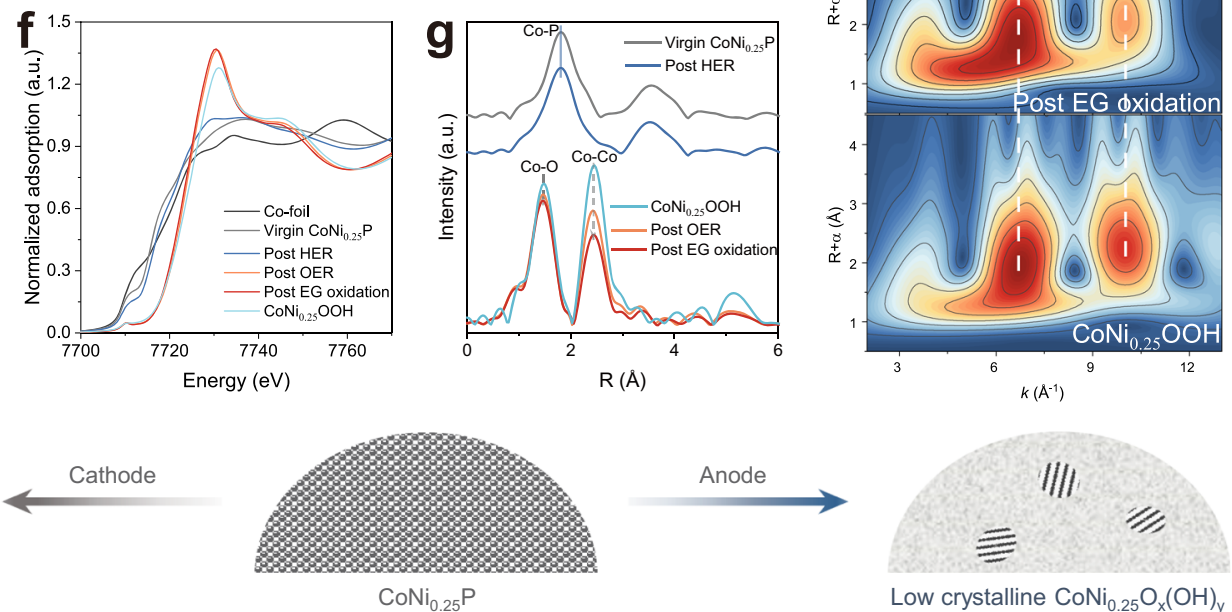

Fig. 5 Catalytic stability and structural evolution of $\mathbf{C o N i}_{\mathbf{0 . 2 5}} \mathbf{P}$ catalyst. a Chronoamperometric stability test for EG oxidation at $1.7 \mathrm{~V}$ vS RHE for 13 cycles and $1.5 \mathrm{~V}$ vs RHE for 11 cycles. The electrolyte was refreshed every $3 \mathrm{~h}$. b-d TEM images and corresponding SAED patterns of CoNio.25 P after HER (b), OER (c), and EG oxidation (d) reaction for $1 \mathrm{~h}$. e Raman spectra, $\mathbf{f}$ Co K-edge XANES profiles, $\mathbf{g}$ Co K-edge EXAFS spectra, and $\mathbf{h}$ Wavelet transforms for Co Kedge EXAFS spectra for virgin and spent $\mathrm{CoNi}_{0.25} \mathrm{P}$. i Schematic illustration of the structural evolution of $\mathrm{CoNi}_{0.25} \mathrm{P}$ catalyst under reaction conditions.

$\mathrm{CoNi}_{0.25} \mathrm{P}$ is completed within $1 \mathrm{~h}$ and stabilized in the following running cycles (Supplementary Fig. 36). This structural evolution might account for the catalyst activation process and the advantageous performance of $\mathrm{CoNi}_{0.25} \mathrm{P}$ compared with the crystalline $\mathrm{CoNi}_{0.25} \mathrm{OOH}$ for $\mathrm{EG}$ oxidation ${ }^{39}$.

\section{Discussion}

We demonstrate an electrocatalytic upcycling strategy for PET waste to produce valuable $\mathrm{H}_{2}$, PTA, and KDF. Preliminary TEA highlights the economic possibility of this process at commercially relevant current densities $\left(>100 \mathrm{~mA} \mathrm{~cm}^{-2}\right)$. An optimized $\mathrm{CoNi}_{0.25} \mathrm{P} / \mathrm{NF}$ material was synthesized that achieves high current densities of $\sim 350 \mathrm{~mA} \mathrm{~cm}^{-2}$ at $1.7 \mathrm{~V}$ vs RHE in an H-cell and $500 \mathrm{~mA} \mathrm{~cm}^{-2}$ at $\sim 1.8 \mathrm{~V}$ cell voltage in a MEA, with high formate selectivity $(>80 \%)$ and FE $(>80 \%)$. The advantageous performance for EG oxidation can be attributed to the structural evolution of $\mathrm{CoNi}_{0.25} \mathrm{P}$ catalyst toward low-crystalline $\mathrm{CoNi}$ oxyhydroxide. This work may open a route for profitable and sustainable preparation of value-added commodity chemicals and clean $\mathrm{H}_{2}$ fuel from plastic waste.

\section{Methods}

Synthesis of catalysts. First, the NF $(3 \times 4 \mathrm{~cm})$ pieces were washed with ethanol, $0.5 \mathrm{M} \mathrm{HCl}$, and deionized water, which were used as both work and counter electrodes for electrodeposition in a three-electrode system with a saturated calomel reference electrode (SCE). Typically, the $\mathrm{CoNi}_{0.25}(\mathrm{OH})_{2} / \mathrm{NF}$ was prepared in an aqueous solution with $100 \mathrm{mM} \mathrm{Co}\left(\mathrm{NO}_{3}\right)_{2}$ and $25 \mathrm{mM} \mathrm{Ni}\left(\mathrm{NO}_{3}\right)_{2}$ by applying a constant current of $-80 \mathrm{~mA}$ for $300 \mathrm{~s}$. Then, the $\mathrm{CoNi}_{0.25}(\mathrm{OH})_{2} / \mathrm{NF}$ material was phosphorated at $300^{\circ} \mathrm{C}$ in argon atmosphere for $2 \mathrm{~h}$ using $\mathrm{NaH}_{2} \mathrm{PO}_{2}$ as phosphorus source to obtain $\mathrm{CoNi}_{0.25} \mathrm{P} / \mathrm{NF}$. The loading of metal hydroxide was calculated to be $2.85 \pm 0.13 \mathrm{mg} \mathrm{cm}^{-2}$. The other electrodes were also prepared by similar procedures with varying concentration of $\mathrm{Ni}$ precursor (Supplementary Table 4).

Material characterizations. Scanning electron microscope (SEM) images of materials were acquired on Zeiss Supra 55. Transmission electron microscope (TEM) images and selected area electron diffraction (SAED) pattern were acquired on FEI TECNAI G ${ }^{2}$ at $200 \mathrm{keV}$. X-ray diffraction (XRD) patterns were recorded on a Bruker D8 Advance diffractometer at $40 \mathrm{~mA}$ and $40 \mathrm{kV}$ using $\mathrm{Cu}$ Ka radiation. $\mathrm{X}$-ray photoelectron spectroscopy (XPS) was performed on a Kratos Axis Supra 
using monochromatic $\mathrm{Al} \mathrm{Kalph} \mathrm{source}(150 \mathrm{~W})$. Metal contents in catalysts were determined by ICP-AES on a Thermo ICAP6300 Radial.

Electrochemical evaluation. All electrochemical experiments were performed in an $\mathrm{H}$-type cell separated by anion exchange membrane (Sustainion ${ }^{\varpi}$ 37-50, Dioxide Materials) on an electrochemical workstation (CHI 760E, CH Instruments, Inc.). The powder catalysts $\left(20 \% \mathrm{Pt} / \mathrm{C}\right.$ (Johnson Matthey) and $\mathrm{RuO}_{2}$ (Alfa Aesar)) were dispersed in aqueous isopropanol solution with Nafion by sonification and sprayed on carbon fiber paper (CFP) with a mass loading of $1 \pm 0.1 \mathrm{mg} \mathrm{cm}^{-2}$. The geometric area of self-supported catalysts and CFP-supported catalysts is $1 \mathrm{~cm} \times 1 \mathrm{~cm}$ for all experiments. The tests were carried out in a three-electrode system, using saturated $\mathrm{Ag} / \mathrm{AgCl}$ and platinum foil as reference and counter electrodes, respectively. All potentials measured against $\mathrm{Ag} / \mathrm{AgCl}$ were converted to the reversible hydrogen electrode (RHE) scale using $E_{\mathrm{RHE}}=E_{\mathrm{Ag} / \mathrm{AgCl}}+0.197+0.059 \mathrm{pH}$. Solution resistance was determined by potentiostatic electrochemical impedance spectroscopy and manually compensated for polarization curves.

The EG oxidation reactions were carried out at potentiostatic mode without iR compensation. After reactions, the concentration of substrate and products were quantified by HPLC (Angilent 1260) equipped with organic acid column (Coregel $87 \mathrm{H} 3$ ) using $5 \mathrm{mM}$ aqueous $\mathrm{H}_{2} \mathrm{SO}_{4}$ as mobile phase. The Faradaic efficiency (FE), formate selectivity, and productivity were calculated with the following equations:

$$
\mathrm{FE}(\%)=100 \% \times \frac{\text { mole of produced product }}{\text { total charge passed } /\left(n \times 96485 \mathrm{C} \mathrm{mol}^{-1}\right)}
$$

$$
\text { Formate selectivity }(\%)=100 \% \times \frac{\text { mole of produced formate } / 2}{\text { mole of converted EG }}
$$

Formate productivity $\left(\mathrm{mmol} \mathrm{cm}{ }^{-2} \mathrm{~h}^{-1}\right)=\frac{\text { amount of produced formate }(\mathrm{mmol})}{\text { area of anode }\left(\mathrm{cm}^{2}\right) \times \text { reaction time }(\mathrm{h})}$

where $n$ is the number of electron transfer for each product formation, $n=3$ for formate, $n=4$ for glycollate; $96485 \mathrm{C} \mathrm{mol}^{-1}$ is the Faraday constant.

The configuration of membrane-electrode assembly (MEA) electrolyzer was depicted in Supplementary Fig. 21 and composed of metal housings, gaskets, asprepared catalysts, and AEM. The electrochemical performance testing of the MEA electrolyzer was performed on an electrochemical workstation with a power amplifier (CS1005, CorrTest).

Hydrolysis of PET. For depolymerization of PET, $6.3 \mathrm{~g}$ dried powder $\left(\mathrm{PET}^{\mathrm{TM}} \mathrm{CB}\right.$ 102,300 mesh, Dupont) was dispersed in $100 \mathrm{~mL}$ of $2 \mathrm{M} \mathrm{KOH}$ aqueous solution in a flask. Then, the flask was sealed with a rubber stopper and heated on a hotplate at $60^{\circ} \mathrm{C}$ with stirring $(1500 \mathrm{rpm})$ for specific time $(3,6,12,18 \mathrm{~h})$. After reactions, the yields of EG and PTA in PET hydrolysate were determined by HPLC.

Products separation from PET electrolyte. The obtained PET hydrolysate was electrolyzed in MEA electrolyzer at $1.7 \mathrm{~V}$ for converting EG into formate. After reaction, anhydrous formic acid was added into $\mathrm{PET}$ electrolyte to adjust the $\mathrm{pH}$ to 3. Meanwhile, white PTA was precipitated from the electrolyte, which was subsequently filtered by membrane $(0.22 \mu \mathrm{m})$ and washed with deionized water. The filtrate containing formate and formic acid were concentrated with rotary evaporation $\left(-0.1 \mathrm{MPa}, 50^{\circ} \mathrm{C}\right)$ to remove water. The hot oversaturated solution was immediately filtered with a filter paper and cooled at $4{ }^{\circ} \mathrm{C}$ for the crystallization of potassium diformate (KDF). Finally, the as-obtained PTA and KDF were dried in vacuum oven at $60^{\circ} \mathrm{C}$.

\section{Data availability}

Additional data related to this study are available from the corresponding authors on reasonable request. Source data are provided with this paper.

Received: 10 April 2021; Accepted: 9 July 2021; Published online: 17 August 2021

\section{References}

1. Geyer, R., Jambeck, J. R. \& Law, K. L. Production, use, and fate of all plastics ever made. Sci. Adv. 3, e1700782 (2017).

2. Uekert, T., Kasap, H. \& Reisner, E. Photoreforming of nonrecyclable plastic waste over a carbon nitride/nickel phosphide catalyst. J. Am. Chem. Soc. 141, 15201-15210 (2019).

3. Editorial. Plastic upcycling. Nat. Catal. 2, 945-946 (2019).

4. Kane, I. A. et al. Seafloor microplastic hotspots controlled by deep-sea circulation. Science 368, 1140-1145 (2020).

5. Rahimi, A. \& Garcia, J. M. Chemical recycling of waste plastics for new materials production. Nat. Rev. Chem. 1, 0046 (2017).
6. Li, L. Z. et al. Effective uptake of submicrometre plastics by crop plants via a crack-entry mode. Nat. Sustain. 3, 929-937 (2020).

7. Wei, R. et al. Possibilities and limitations of biotechnological plastic degradation and recycling. Nat. Catal. 3, 867-871 (2020).

8. Jing, Y. et al. Towards the circular economy: converting aromatic plastic waste back to arenes over a $\mathrm{Ru} / \mathrm{Nb}_{2} \mathrm{O}_{5}$ catalyst. Angew. Chem. Int. Ed. 60, 5527-5535 (2021).

9. Haussler, M., Eck, M., Rothauer, D. \& Mecking, S. Closed-loop recycling of polyethylene-like materials. Nature 590, 423-427 (2021).

10. Tournier, V. et al. An engineered PET depolymerase to break down and recycle plastic bottles. Nature 580, 216-219 (2020).

11. Ugduler, S. et al. Towards closed-loop recycling of multilayer and coloured PET plastic waste by alkaline hydrolysis. Green Chem. 22, 5376-5394 (2020).

12. Zhang, F. et al. Polyethylene upcycling to long-chain alkylaromatics by tandem hydrogenolysis/aromatization. Science 370, 437-441 (2020).

13. Kratish, Y., Li, J., Liu, S., Gao, Y. \& Marks, T. J. Polyethylene terephthalate deconstruction catalyzed by a carbon-supported single-site molybdenumdioxo complex. Angew. Chem. Int. Ed. 59, 19857-19861 (2020).

14. Wang, L., Nelson, G. A., Toland, J. \& Holbrey, J. D. Glycolysis of PET using 1,3-dimethylimidazolium-2-carboxylate as an organocatalyst. ACS Sustain. Chem. Eng. 8, 13362-13368 (2020).

15. Uekert, T., Kuehnel, M. F., Wakerley, D. W. \& Reisner, E. Plastic waste as a feedstock for solar-driven $\mathrm{H}_{2}$ generation. Energy Environ. Sci. 11, 2853-2857 (2018).

16. Uekert, T., Pichler, C. M., Schubert, T. \& Reisner, E. Solar-driven reforming of solid waste for a sustainable future. Nat. Sustain. 4, 383-391 (2020).

17. Lin, C.-Y., Huang, S.-C., Lin, Y.-G., Hsu, L.-C. \& Yi, C.-T. Electrosynthesized Ni-P nanospheres with high activity and selectivity towards photoelectrochemical plastics reforming. Appl. Catal. B Environ. 296, 120351 (2021).

18. Bajada, M. A. et al. A precious-metal-free hybrid electrolyzer for alcohol oxidation coupled to $\mathrm{CO}_{2}$-to-syngas conversion. Angew. Chem. Int. Ed. 59, 15633-15641 (2020).

19. Zhou, H. et al. Selectively upgrading lignin derivatives to carboxylates through electrochemical oxidative $\mathrm{C}(\mathrm{OH})-\mathrm{C}$ bond cleavage by a $\mathrm{Mn}$-doped cobalt oxyhydroxide catalyst. Angew. Chem. Int. Ed. 60, 8976-8982 (2021)

20. Liu, W. J. et al. Efficient electrochemical production of glucaric acid and $\mathrm{H}_{2}$ via glucose electrolysis. Nat. Commun. 11, 265 (2020).

21. Sherbo, R. S., Delima, R. S., Chiykowski, V. A., MacLeod, B. P. \& Berlinguette, C. P. Complete electron economy by pairing electrolysis with hydrogenation. Nat. Catal. 1, 501-507 (2018).

22. Han, X. T. et al. Electrocatalytic oxidation of glycerol to formic acid by $\mathrm{CuCo}_{2} \mathrm{O}_{4}$ spinel oxide nanostructure catalysts. ACS Catal. 10, 6741-6752 (2020).

23. Li, Y., Wei, X., Chen, L., Shi, J. \& He, M. Nickel-molybdenum nitride nanoplate electrocatalysts for concurrent electrolytic hydrogen and formate productions. Nat. Commun. 10, 5335 (2019).

24. Chen, Y. X. et al. Nanotechnology makes biomass electrolysis more energy efficient than water electrolysis. Nat. Commun. 5, 4036 (2014).

25. Chen, W. et al. Activity origins and design principles of nickel-based catalysts for nucleophile electrooxidation. Chem 6, 2974-2993 (2020).

26. Lu, Y. et al. Tuning the selective adsorption site of biomass on $\mathrm{Co}_{3} \mathrm{O}_{4}$ by $\mathrm{Ir}$ single atoms for electrosynthesis. Adv. Mater. 33, e2007056 (2021).

27. $\mathrm{Na}$, J. et al. General technoeconomic analysis for electrochemical coproduction coupling carbon dioxide reduction with organic oxidation. Nat. Commun. 10, 5193 (2019).

28. Additives, E. P. O. et al. Safety of potassium diformate (Formi LHS) as a feed additive for sows, from ADDCON EUROPE GmbH. EFSA J. 18, e06339 (2020).

29. Huyghebaert, G., Ducatelle, R. \& Van Immerseel, F. An update on alternatives to antimicrobial growth promoters for broilers. Vet. J. 187, 182-188 (2011).

30. Lum, Y. et al. Tuning $\mathrm{OH}$ binding energy enables selective electrochemical oxidation of ethylene to ethylene glycol. Nat. Catal. 3, 14-22 (2020).

31. De Luna, P. et al. What would it take for renewably powered electrosynthesis to displace petrochemical processes? Science 364, eaav3506 (2019).

32. Leow, W. R. et al. Chloride-mediated selective electrosynthesis of ethylene and propylene oxides at high current density. Science 368, 1228-1233 (2020).

33. Shi, Y. M., Li, M. Y., Yu, Y. F. \& Zhang, B. Recent advances in nanostructured transition metal phosphides: synthesis and energy-related applications. Energy Environ. Sci. 13, 4564-4582 (2020).

34. Zhang, B., Huang, C., Huang, Y., Liu, C. \& Chong, X. Potential-tuned selective electrosynthesis of azoxy-, azo- and amino-aromatics over a CoP nanosheet cathode. Natl Sci. Rev. 7, 285-295 (2020).

35. King, L. A. et al. A non-precious metal hydrogen catalyst in a commercial polymer electrolyte membrane electrolyser. Nat. Nanotechnol. 14, 1071-1074 (2019).

36. Kwon, Y., Lai, S. C., Rodriguez, P. \& Koper, M. T. Electrocatalytic oxidation of alcohols on gold in alkaline media: base or gold catalysis? J. Am. Chem. Soc. 133, 6914-6917 (2011). 
37. Dai, C. C. et al. Electrochemical production of lactic acid from glycerol oxidation catalyzed by AuPt nanoparticles. J. Catal. 356, 14-21 (2017).

38. Dionigi, F. et al. In-situ structure and catalytic mechanism of NiFe and CoFe layered double hydroxides during oxygen evolution. Nat. Commun. 11, 2522 (2020).

39. Li, S. et al. A glass-ceramic with accelerated surface reconstruction toward the efficient oxygen evolution reaction. Angew. Chem. Int. Ed. 60, 3773-3780 (2021).

40. Wei, C. et al. Recommended practices and benchmark activity for hydrogen and oxygen electrocatalysis in water splitting and fuel cells. Adv. Mater. 31, e1806296 (2019).

41. Salvatore, D. A. et al. Designing anion exchange membranes for $\mathrm{CO}_{2}$ electrolysers. Nat. Energy 6, 339-348 (2021).

42. Xiang, $\mathrm{K}$. et al. Boosting $\mathrm{H}_{2}$ generation coupled with selective oxidation of methanol into value-added chemical over cobalt hydroxide@hydroxysulfide nanosheets electrocatalysts. Adv. Funct. Mater. 30, 1909610 (2020).

43. Wei, X., Li, Y., Chen, L. \& Shi, J. Formic acid electro-synthesis by concurrent cathodic $\mathrm{CO}_{2}$ reduction and anodic $\mathrm{CH}_{3} \mathrm{OH}$ oxidation. Angew. Chem. Int. Ed. 60, 3148-3155 (2021).

44. Hao, J. et al. In situ facile fabrication of $\mathrm{Ni}(\mathrm{OH})_{2}$ nanosheet arrays for electrocatalytic co-production of formate and hydrogen from methanol in alkaline solution. Appl. Catal. B Environ. 281, 119510 (2021).

45. Walker, T. W. et al. Recycling of multilayer plastic packaging materials by solvent-targeted recovery and precipitation. Sci. Adv. 6, eaba7599 (2020).

46. Bushuyev, O. S. et al. What should we make with $\mathrm{CO}_{2}$ and how can we make it? Joule 2, 825-832 (2018).

47. Cao, D. et al. Operando X-ray spectroscopy visualizing the chameleon-like structural reconstruction on an oxygen evolution electrocatalyst. Energy Environ. Sci. 14, 906-915 (2021).

48. Fabbri, E. et al. Dynamic surface self-reconstruction is the key of highly active perovskite nano-electrocatalysts for water splitting. Nat. Mater. 16, 925-931 (2017).

49. Wakerley, D. W. et al. Solar-driven reforming of lignocellulose to $\mathrm{H}_{2}$ with a CdS/CdO photocatalyst. Nat. Energy 2, 17021 (2017).

50. Wang, Y. et al. Unveiling catalytic sites in a typical hydrogen photogeneration system consisting of semiconductor quantum dots and $3 \mathrm{~d}$-metal ions. J. Am. Chem. Soc. 142, 4680-4689 (2020).

51. Rosser, T. E. et al. Enhanced oxygen evolution catalysis by aluminium-doped cobalt phosphide through in situ surface area increase. Catal. Sci. Technol. 10, 2398-2406 (2020).

52. Saadi, F. H. et al. Operando spectroscopic analysis of CoP films electrocatalyzing the hydrogen-evolution reaction. J. Am. Chem. Soc. 139 12927-12930 (2017).

53. Moysiadou, A., Lee, S., Hsu, C. S., Chen, H. M. \& Hu, X. Mechanism of oxygen evolution catalyzed by cobalt oxyhydroxide: cobalt superoxide species as a key intermediate and dioxygen release as a rate-determining step. J. Am. Chem. Soc. 142, 11901-11914 (2020).

\section{Acknowledgements}

This work was supported by the National Natural Science Foundation of China (Grant No. 21978147, 21935001) and Beijing Municipal Natural Science Foundation (2214063). The authors thank the BL1W1B in the Beijing Synchrotron Radiation Facility (BSRF).

\section{Author contributions}

H.D. supervised this project and wrote the manuscript. H.Z. and Z.-H. L. conceived the concept, designed the experiments, and wrote the manuscript. Y. R. and H.Z. performed the experiments. M.X. analyzed the XAFS data. Y. W. performed the Rietveld refinement of XRD. R.G. and X.K. helped with the experiments, discussed and reviewed the manuscript. L.Z. helped with the XAFS analysis, discussed and reviewed the manuscript

\section{Competing interests}

The authors declare no competing interests.

\section{Additional information}

Supplementary information The online version contains supplementary material available at https://doi.org/10.1038/s41467-021-25048-x.

Correspondence and requests for materials should be addressed to H.D.

Peer review information Nature Communications thanks Bert Weckhuysen, Andreu Cabot and the other anonymous reviewers for their contribution to the peer review of this work

Reprints and permission information is available at http://www.nature.com/reprints

Publisher's note Springer Nature remains neutral with regard to jurisdictional claims in published maps and institutional affiliations.

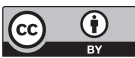

Open Access This article is licensed under a Creative Commons Attribution 4.0 International License, which permits use, sharing, adaptation, distribution and reproduction in any medium or format, as long as you give appropriate credit to the original author(s) and the source, provide a link to the Creative Commons license, and indicate if changes were made. The images or other third party material in this article are included in the article's Creative Commons license, unless indicated otherwise in a credit line to the material. If material is not included in the article's Creative Commons license and your intended use is not permitted by statutory regulation or exceeds the permitted use, you will need to obtain permission directly from the copyright holder. To view a copy of this license, visit http://creativecommons.org/ licenses/by/4.0/.

(C) The Author(s) 2021 